\title{
Scoparone Induces Expression of Pluripotency Transcription Factors SOX2 and NANOG in Dermal Papilla Cells
}

\author{
NATTHA SUWANPRAKORN ${ }^{1,2}$, PITHI CHANVORACHOTE ${ }^{3,4}$, THITIPORN TONGYEN ${ }^{2}$, \\ BOONCHOO SRITULARAK ${ }^{5}$ and PICHIT SUVANPRAKORN ${ }^{1,2}$ \\ ${ }^{1}$ Division of Dermatology, Chulabhorn International College of Medicine, \\ Thammasat University, Pathum Thani, Thailand; \\ ${ }^{2}$ Pan Rajdhevee Group Public Co., Ltd., Pathum Thani, Thailand; \\ ${ }^{3}$ Cell-Based Drug and Health Product Development Research Unit, \\ Faculty of Pharmaceutical Sciences, Chulalongkorn University, Bangkok, Thailand; \\ ${ }^{4}$ Department of Pharmacology and Physiology, Faculty of Pharmaceutical Sciences, \\ Chulalongkorn University, Bangkok, Thailand; \\ ${ }^{5}$ Department of Pharmacognosy and Pharmaceutical Botany, \\ Faculty of Pharmaceutical Sciences, Chulalongkorn University, Bangkok, Thailand
}

\begin{abstract}
Background/aim: Dermal papilla cells (DPCs) regulate hair follicle development. We aimed to investigate the effect of scoparone from Dendrobium densiflorum on $D P C s$ in the induction of stem cell properties and pluripotency-related proteins. Materials and methods: DPC viability was evaluated by the MTT assay. Apoptosis or necrosis of DPCs was determined by Hoecsht33342/PI nuclear staining analysis. Expression of OCT4, NANOG and SOX2 genes was determined using Real-Time Polymerase Chain Reaction (PCR). Immunocytochemistry and western blot analysis were performed to determine pluripotency related proteins. Results: Scoparone increased the expression of pluripotency related transcription factors SOX2 and NANOG, while it had minimal effects on OCT4 levels. Scoparone exerted its stemness-enhancing activity through the up-regulation of Akt-dependent inhibition of GSK3 $\beta$, resulting in increased cellular levels of $\beta$-catenin. Conclusion: Our results show a potential novel activity and mechanism of action of scoparone on human DPCs that could facilitate the development of hair enrichment approaches.
\end{abstract}

This article is freely accessible online.

Correspondence to: Pithi Chanvorachote, Department of Pharmacology and Physiology, Faculty of Pharmaceutical Sciences, Chulalongkorn University, Bangkok 10330, Thailand. Tel: +662 2188344, e-mail: pithi_chan@yahoo.com

Key Words: Scoparone, dermal papilla, pluripotency, stemness, NANOG, SOX2.
Hair disorders like androgenetic alopecia frequently affect the overall well-being and appearance of an individual; there is now ongoing intensive research covering hair cell biology and the discovery of new compounds benefiting hair growth and maintenance (1). In the mesenchymal compartment of hair follicles, dermal papilla cells (DPCs) at the base play a role as a key signaling center in controlling hair follicle development and sustaining the growing phase of the hair cycle $(2,3)$. DPCs are also recognized as multipotent stem cells and it has been shown that their stemness is linked to their ability in forming hair follicles (4). In recent years, the $\mathrm{Wnt} / \beta$-catenin signaling has been demonstrated to provide strong regulatory functions on hair follicle morphogenesis and hair regeneration (5-7). Wnt/ $\beta$-catenin is known to be an important coregulator of the three master transcription factors (OCT4, NANOG, and SOX2) that promote selfrenewal of embryonic stem cells (8-10).

The up-stream regulatory control of $\mathrm{Wnt} / \beta$-catenin signaling that gathered attention for hair treatment therapeutic approaches is the phosphatidylinositol 3-kinase (PI3K)/protein kinase B (Akt) axis (11). The induction of PI3K/Akt inhibits the ubiquitin-proteasomal degradation of $\beta$-catenin by inactivating GSK3$\beta(12)$, resulting in the increase of cellular levels of $\beta$-catenin (12). In addition, PI3K/Akt and Wnt/ $\beta$ catenin signals are known to facilitate cell growth and survival (13). Cultivation of human DPCs in the presence of a glycogen synthase kinase- $3 \beta$ inhibitor resulted in the induction of $\mathrm{Wnt} / \beta$-catenin pathway leading to stable hair inductive ability (14). Likewise, another study has demonstrated that basic FGF could induce hair growth $(15,16)$. Wnt/ $\beta$-catenin has been found to be an important signaling molecule for hair growth and has the ability to promote the three master 
transcription factors that enhance self-renewal in DPCs (3, $17)$; it is therefore likely that Wnt $\beta$-catenin signaling will have a positive role in the stemness of DPCs.

Scoparone is a coumarin derivative (Figure 1A) isolated from the Dendrobium densiflorum (Figure 1B). Previous studies have revealed many pharmacological beneficial effects, such as promoting bilirubin clearance as well as anticoagulant, anti-inflammatory, anti-allergic and antioxidant activities (18). However, there are no studies focusing on the effects of scoparone on the stemness of DPCs. Therefore, the aim of this study is to investigate the effects of scoparone on the stemness of dermal papilla cells and to explore its possible mechanism.

\section{Materials and Methods}

Compound and reagents. Scoparone was isolated from D. densiforum. Dendrobium densiflorum Lindl. (Orchidaceae) was purchased from Chatuchak market, Bangkok, Thailand in November 2012. Plant identification was performed by Dr. Boonchoo Sritularak. A voucher specimen (BS-112555) is at the Department of Pharmacognosy and Pharmaceutical botany, Faculty of Pharmaceutical Sciences, Chulalongkorn University, Thailand. The whole plant of $D$. densiflorum $(600 \mathrm{~g})$ was dried and powdered, and then macerated with $\mathrm{MeOH}$ to give $30 \mathrm{~g}$ of $\mathrm{MeOH}$ extract after removal of the solvent. The $\mathrm{MeOH}$ extract was fractionated by vacuum liquid chromatography (silica gel, hexane-EtOAc, gradient) to give 8 fractions (A-H). Fraction E (2.0 g) was separated by column chromatography (silica gel, hexaneEtOAc, gradient) and further purified on Sephadex LH-20 (acetone) to give Scoparone $(61 \mathrm{mg})$. The structure of scoparone was determined by comparison of its NMR data with previously reported values. (19) Fetal bovine serum (FBS), penicillin/streptomycin, L-glutamine, phosphate buffered saline (PBS) and trypsin were purchased from GIBCO (Grand Island, NY, USA). Propidium iodide (PI) and Hoechst 33342 were obtained from Molecular Probes, Inc. (Eugene, OR, USA). 3-(4,5-dimethyl-thiazol-2-yl)-2,5-Diphenyl tetrazolium bromide (MTT) was obtained from Sigma Chemical, Inc. (St. Louis, MO, USA). Antibody for Akt, activated Akt (phosphorylated Akt at Ser 473), total Akt, inactivated glycogen synthase kinase $3 \beta$ (phosphorylated GSK3 $\beta$ at Ser 9), GSK3 $\beta$, GAPDH, and peroxidaseconjugated secondary antibodies were purchased from Cell Signaling Technology, Inc. (Danvers, MA, USA).

Cell culture. Immortalized dermal papilla cells (DPCs) were acquired from Applied Biological Materials Inc. (Richmond, BC, Canada). DPCs were cultured in Dulbecco's modified Eagle's medium (DMEM) (Gibco, Grand Island, NY, USA) supplemented with $10 \% \mathrm{FBS}, 100$ units/ml penicillin/streptomycin and $2 \mathrm{mM} \mathrm{L-}$ glutamine. The cells were incubated at $37^{\circ} \mathrm{C}$ with $5 \% \mathrm{CO}_{2}$, in a humidified incubator. For subcultures, cells were washed by $1 \times$ PBS and detached using a $0.25 \%$ trypsin and $0.53 \mathrm{mM}$ EDTA solution.

Cytotoxicity assay. Cells were seeded in 96-well plates at a density of $1 \times 10^{4}$ cells/well. They were then treated with various concentrations of scoparone for $24 \mathrm{~h}$. DMEM was removed and 100 $\mu \mathrm{l}$ of DMSO were added to dissolve the formed formazan crystals. Color intensity of the crystal formazan product was measured by spectrophotometry at $570 \mathrm{~nm}$ using a microplate reader (Anthros,
Dur ham, NC, USA); the percentage of cell viability was calculated in relation to untreated cells.

Cell apoptosis assay. After treatment, apoptotic cell death was determined using nuclear staining with Hoechst 33342 and PI. Cells were stained with $10 \mu \mathrm{M}$ of Hoechst 33342 and $5 \mu \mathrm{M}$ of PI for 30 $\min$ at $37^{\circ} \mathrm{C}$. Cells were then visualized and imaged using a fluorescence microscope (Olympus DP70, Melville, NY, USA). Three random fields were captured.

Quantification of DNA by Real-Time Polymerase Chain Reaction $(P C R)$. DPCs were seeded in 6-well plate at a density of $7 \times 10^{5}$ cells $/ \mathrm{ml}$ for $24 \mathrm{~h}$. Then, cells were treated with scoparone at concentrations of $0,2.5,5$ and $10 \mu \mathrm{M}$. Cell pellets were collected for RNA extraction by trypsinization. Cells were extracted of RNA by QIAGEN RNeasy mini kit, according to the manufacturer's instructions. cDNA was then synthesized by the extracted RNA by following the QuantiTect Reverse Transcription protocol kit. cDNA (100 ng/well) was used as a template in $\mathrm{qPCR}$ reactions with oligonucleotides specific for the genes of interest (Figure 2A). The relative values were calculated by target genes to the housekeeping gene.

Western blot. After treatment (12 and $24 \mathrm{~h})$, the cells $\left(7 \times 10^{5}\right)$ were washed with cold PBS twice and incubated on ice with lysis buffer containing $20 \mathrm{mM}$ Tris- $\mathrm{HCl}(\mathrm{pH} 7.5), 150 \mathrm{mM}$ sodium chloride $(\mathrm{NaCl})$, $10 \%$ glycerol, $1 \mathrm{mM}$ sodium orthovanadate, $50 \mathrm{mM}$ sodium fluoride, $1 \mathrm{mM}$ phenylmethylsulphonyl fluoride and a protease inhibitor cocktail (Roche Molecular Biochemicals, Indianapolis, IN, USA) for $30 \mathrm{~min}$. Cell lysates were collected, and the protein content was determined using the BCA protein assay kit (Bio-Rad Laboratories). Approximately $25 \mu \mathrm{g}$ of protein from each sample was denatured at $95^{\circ} \mathrm{C}$ for $5 \mathrm{~min}$ and loaded onto $10 \%$ SDS-polyacrylamide gels. After gel separation, the proteins were transferred onto $0.45 \mu \mathrm{m}$ Polyvinylidene fluoride (PVDF) membranes (Bio-Rad), and the transferred membranes were incubated with blocking buffer [5\% non-fat dry milk in TBST $(25 \mathrm{mM}$ Tris- $\mathrm{HCl}$ (pH 7.5), $125 \mathrm{mM} \mathrm{NaCl}, 0.05 \%$ Tween 20)] for $1 \mathrm{~h}$ and subsequently incubated with the appropriate specific primary antibody at $4^{\circ} \mathrm{C}$ overnight. Membranes were then washed 3 times for 5 min with TBST and incubated with horseradish peroxidase (HRP)-conjugated anti-rabbit or anti-mouse IgG isotype-specific secondary antibodies in blocking buffer for $2 \mathrm{~h}$ at room temperature. Membranes were then washed again with TBST (3 times for $5 \mathrm{~min}$ ). The Super Signal West Pico Chemiluminescent substrate (Thermo Scientific, Rockford, IL, USA) was used to detect immune complexes and the signal was quantified by densitometry, using ImageJ version 1.52 (National Institute of Health, Bethesda, MD, USA).

Immunocytochemistry. Cells were pretreated with a PI3K inhibitor (50 $\mu \mathrm{M}$ of LY294002 or $5 \mu \mathrm{M}$ of wortmannin). $10 \mu \mathrm{M}$ of Scoparone were then added as described in Figure 3. After treatment, cells were fixed with $4 \%(\mathrm{w} / \mathrm{v})$ paraformaldehyde for 10 $\min$. The cells were then permeabilized by $0.5 \%(\mathrm{v} / \mathrm{v})$ Triton-X for $5 \mathrm{~min}$. Cells were incubated with $10 \%(\mathrm{w} / \mathrm{v})$ FBS for $1 \mathrm{~h}$. Antibodies against $\beta$-catenin (1:100) and SOX2 (1:100) (InvivoGen, San Diego, CA, USA) were added and incubated for $10 \mathrm{~h}$ at $4^{\circ} \mathrm{C}$. Cells were incubated with FITC (Abcam, Cambridge, UK) conjugated Goat Anti-Rabbit secondary antibody (1:250). Nuclei were stained with Hoechst 33342 for 15 min in the dark. Cells were visualized by fluorescence microscopy (Nikon model ECLIPSE Ts2-FL, Tokyo, Japan). 
A<smiles>COc1cc2ccc(=O)oc2cc1OC</smiles>

Scoparone

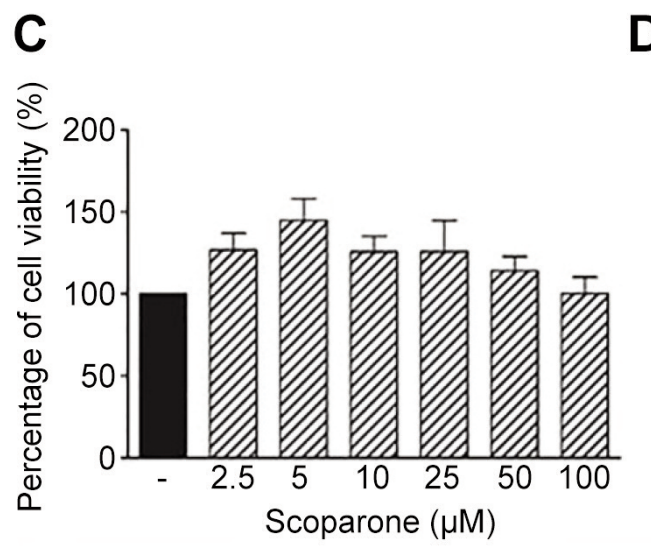

B

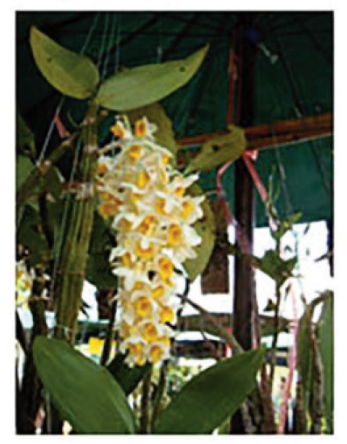

Dendrobium densiflorum

E



0
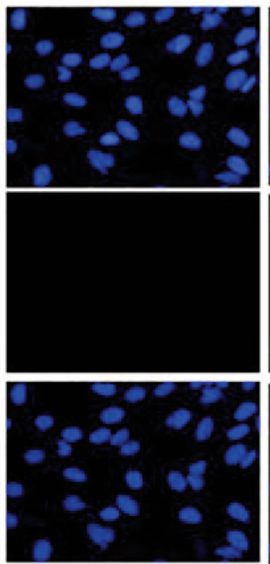

2.5

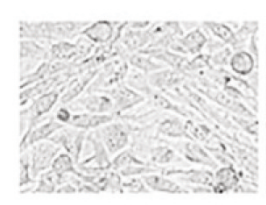

2.5



5

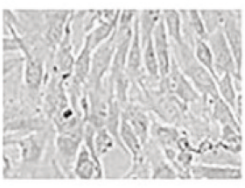

10

\section{Scoparone concentration $(\mu \mathrm{M})$}
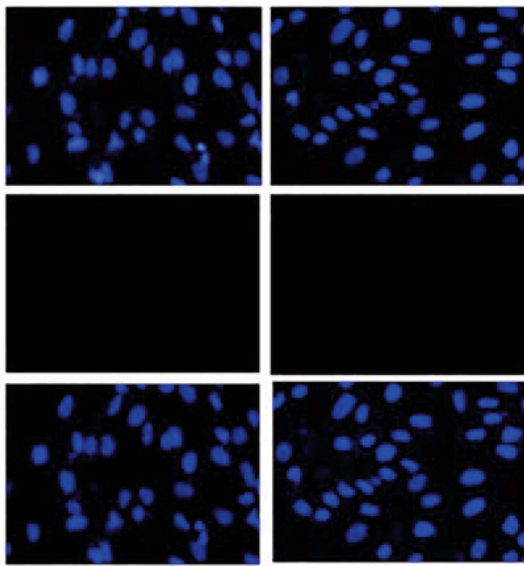

5



10

\section{Scoparone concentration $(\mu \mathrm{M})$}

Figure 1. Chemical structure of Scoparone (A). Dendrobium infundibulum plant (B). Cytotoxic effects of scoparone on immortalized dermal papilla cells were investigated using the MTT assay (C). Characteristic DPCs treated with 0.25, 5 and $10 \mu M$ of scoparone for 24h, visualized under microscopy (D). Scoparone did not induce cellular apoptosis. DPCs were treated with scoparone (0-100 $\mu M)$ for 24 h. Hoechst 33342 and propidium iodide (PI) were added. Cells were visualized under an inverted fluorescent microscope (E).

Statistical analysis. Statistical differences between multiple groups were analyzed using an analysis of variance (ANOVA) followed by the Tukey HSD post-hoc test. The data is presented as the mean \pm standard error of the mean (SEM) of three independent experiments with three replicates per experiment. All $p$-values of less than 0.05 were considered as statistically significant. 


\begin{tabular}{|c|c|c|}
\hline Aene & Forward & Reverse \\
\hline NANOG & 5'-ATGCCTCACACGGAGACTGT-3' & 5'-AAGTGGGTTGTTTGCCTTTG-3' \\
\hline OCT4 & 5'-TCGAGAACCGAGTGAGAGG-3' & 5'-GAACCACACTCGGACCACA-3' \\
\hline SOX2 & 5'-TGATGGAGACGGAGCTGAA-3' & 5'-GGGCTGTITTCTGGTTGC-3' \\
\hline
\end{tabular}
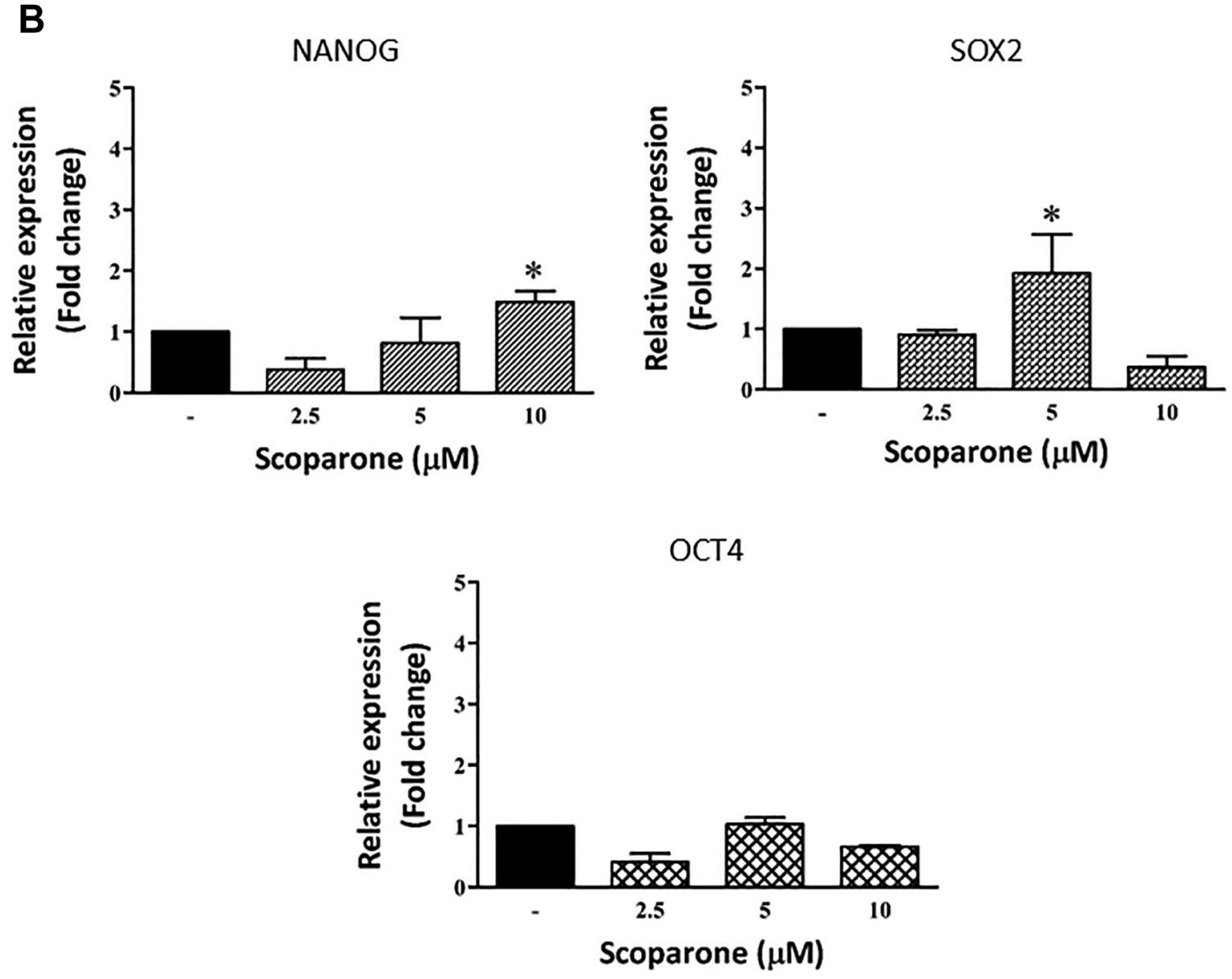

Figure 2. Primer sequences of pluripotency related genes of interest: OCT4, NANOG and SOX2 (A). Scoparone increased the expression of NANOG and SOX2. DPCs were treated with various concentrations of the compound $(0,2.5,5,10 \mu M)$ for 24 h and OCT4, NANOG and SOX2 expression was measured by Real-Time Polymerase Chain Reaction (PCR). Scoparone at concentrations of 5 and $10 \mu M$ significantly increased SOX2 and $N A N O G$ expression in DPCs, compared to untreated controls $(p<0.05)(B)$. Data represent mean $\pm S E M(n=3)$.

\section{Results}

Cytotoxicity of scoparone on human dermal papilla cells. To test the effect of scoparone, derived from Dendrobium densiflorum (Figure 1A, B), we first determined the cytotoxic concentrations of the compound in immortalized human dermal papilla cells (DPCs). Briefly, $80 \%$ confluent DPCs were treated with scoparone $(0,2.5,5,10,25,50$ and $100 \mu \mathrm{M})$ and cell viability was determined after $24 \mathrm{~h}$ by MTT viability assay. Results showed that scoparone at 


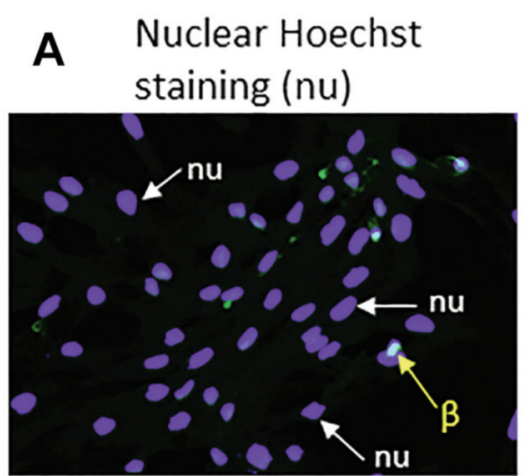

Control



LY294002 $50 \mu \mathrm{M}$

B Nuclear Hoechst staining (nu)



Control

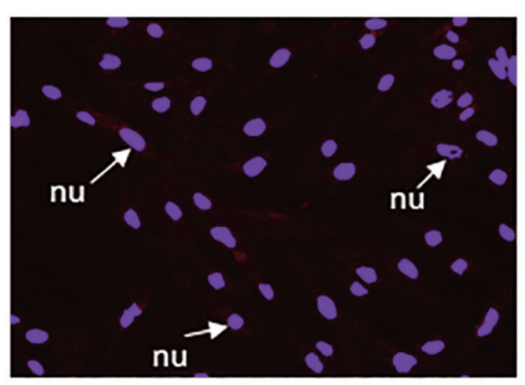

LY294002 $50 \mu \mathrm{M}$ $\beta$-catenin specific staining $(\beta)$

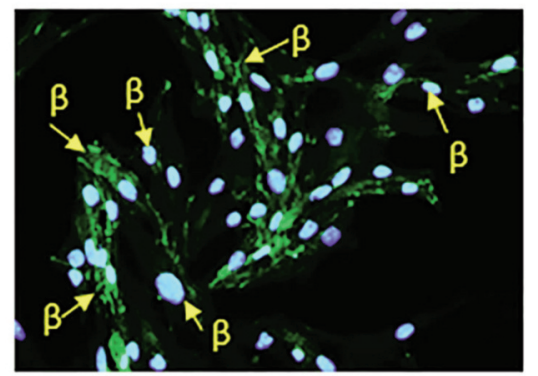

Scoparone $10 \mu \mathrm{M}$

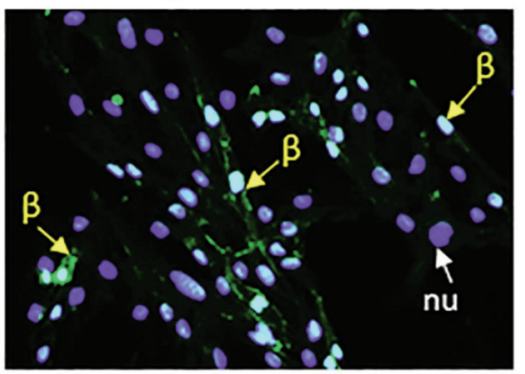

Wortmannin $5 \mu \mathrm{M}$ + scoparone $10 \mu \mathrm{M}$

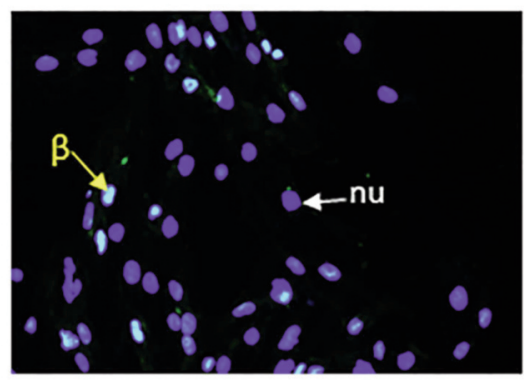

Wortmannin $5 \mu \mathrm{M}$

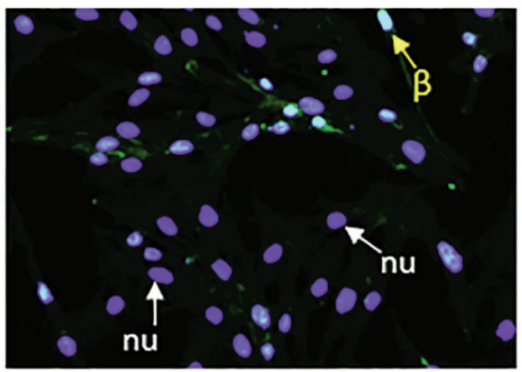

LY294002 $50 \mu \mathrm{M}$

+ scoparone $10 \mu \mathrm{M}$

SOX2 specific staining (so)
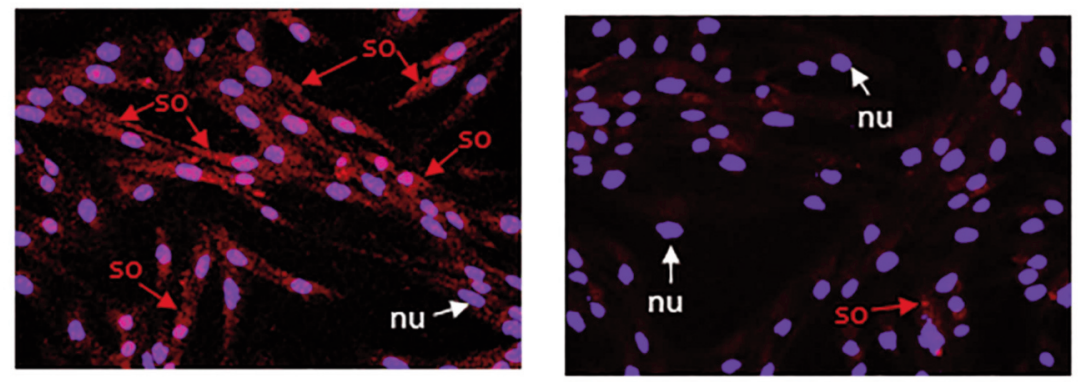

Scoparone $10 \mu \mathrm{M}$

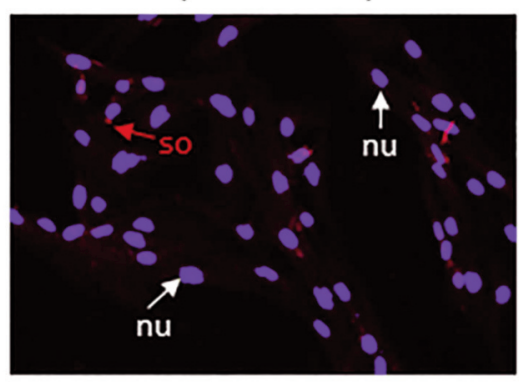

Wortmannin $5 \mu \mathrm{M}$

+ scoparone $10 \mu \mathrm{M}$
Wortmannin $5 \mu \mathrm{M}$



LY294002 $50 \mu \mathrm{M}$

+ scoparone $10 \mu \mathrm{M}$

Figure 3. Scoparone increased the expression of $\beta$-catenin and SOX2 via the PI3K/Akt pathway. Cells were pretreated with PI3K inhibitors and the expression of $\beta$-catenin (A) or SOX2 (B) was measured by immunocytochemistry. Scoparone alone induced expression of $\beta$-catenin and SOX2, compared to controls. In the presence of PI3K inhibitors (LY294002 or wortmannin), $\beta$-catenin and SOX2 were found to be reduced (A, B). 
A 12 hours of treatment

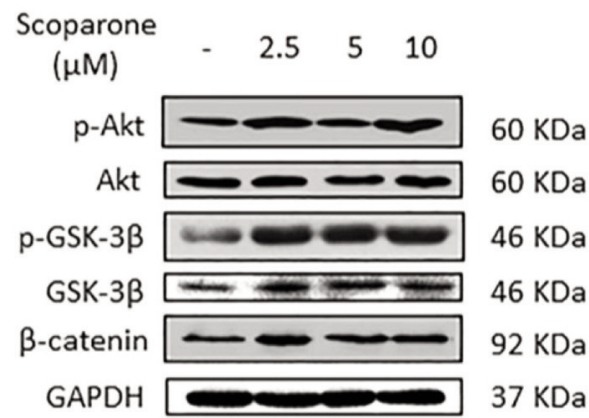

\section{B 24 hours of treatment}

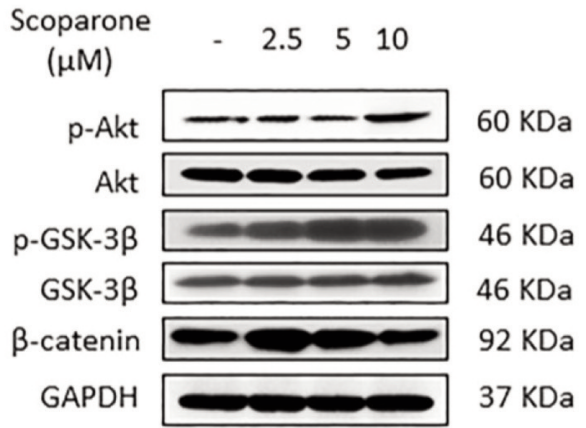

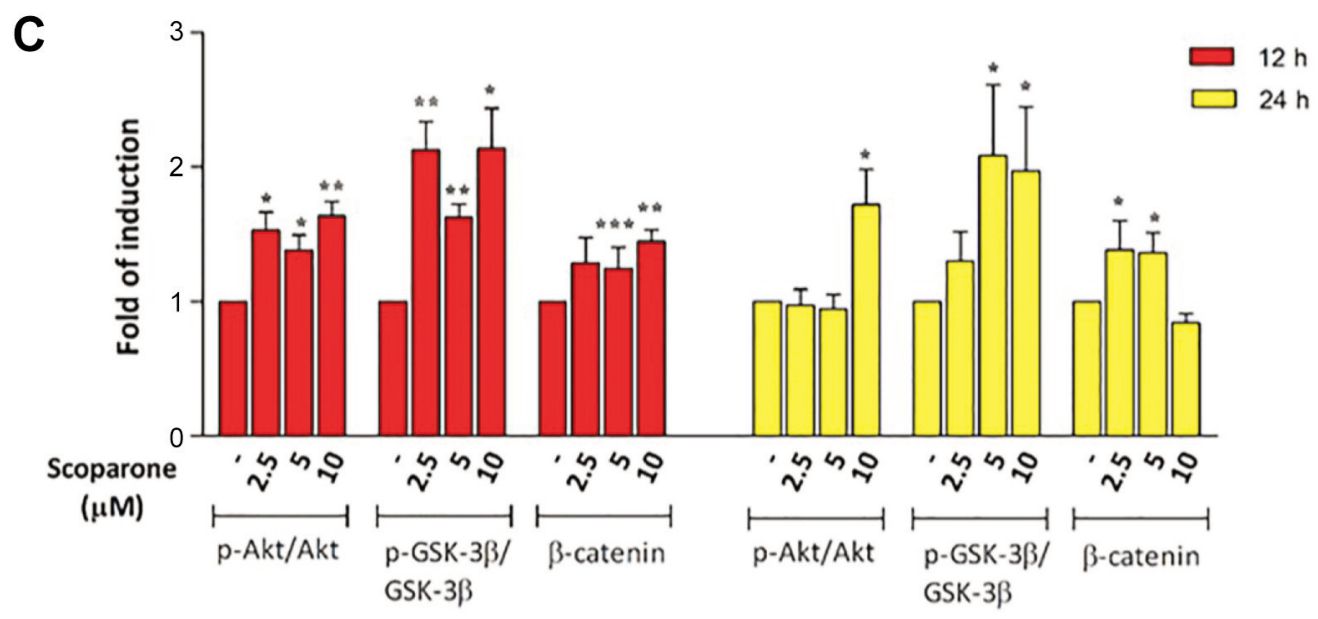

Figure 4. The effect of scoparone on the expression of Wnt/ $\beta$-catenin related proteins. DPCs were treated with scoparone for 12 and 24 h. The expression levels of Akt, phosphorylated Akt, GSK3 $\beta$, phosphorylated GSK3 $\beta, \beta$-catenin and GAPDH in DPCs at 12 and $24 \mathrm{~h}$ were measured by Western blot $(A, B)$. Relative protein levels were calculated by densitometry $(C)$. Data represent mean $\pm S E M(n=3)$. ${ }^{*} p<0.05$ compared to untreated control.

concentrations up to $100 \mu \mathrm{M}$ was considered non-toxic to the cells (Figure 1C). As MTT assay determined the viability of the cells via monitoring function of mitochondrial enzymes, we next confirmed the non-toxic concentrations of the compound by other means. Hoechst 33342 and PI staining were utilized to detect the direct apoptotic and necrotic cell death, respectively. Apoptotic cells that exhibited condensed or fragmented DNA in the nucleus were barely detected in response to $0-100 \mu \mathrm{M}$ scoparone. Results suggested that scoparone at concentrations of $0-100 \mu \mathrm{M}$ did not induce cell death, as indicated by normal nuclei stained with Hoechst and negative PI staining (Figure 1E).

Scoparone increases stem cell transcription factors. Pluripotent stem cell transcription factors are known to exert a direct impact on stemness of stem cells and are widely recognized as positive stem cell markers. In order to evaluate the scoparone's effect on stemness, DPCs were treated with the compound at $0,2.5,5,10 \mu \mathrm{M}$ for $24 \mathrm{~h}$ and were then subjected to an analysis of pluripotency related genes (OCT4, NANOG, and SOX2) by real-time polymerase chain reaction (PCR). Scoparone at concentrations of 5 and $10 \mu \mathrm{M}$ significantly increased SOX2 and NANOG expression in DPCs compared to controls ( $p<0.05$, Figure 2B).

Scoparone increases stemness of DPCs via the PI3K/Akt pathway. Signaling via the PI3K/Akt was known to have crucial roles in the self-renewal of embryonic stem cells (20). In addition, treatment of DPCs with scoparone significantly augmented the stem cell-related transcription factors as shown above. Since Wnt/ $\beta$-catenin signaling has been shown to be the most important signaling in hair regeneration and the $\beta$-catenin stability in the cells is tightly regulated by the function of Akt via its inhibition on $\operatorname{GSK} 3 \beta(21,22)$, we aimed to investigate the potential regulatory activity of scoparone on the PI3K/Akt/ $\beta$-catenin axis in DPCs. The cellular level of active Akt (phosphorylated at Ser 473), total 




Figure 5. Schematic overview of the proposed mechanism of action of scoparone based on evidence from the present study, as well as previous literature. Scoparone has positive effects on the stem cell properties of human DPCs via Akt-dependent induction of cellular $\beta$-catenin. The increased $\beta$-catenin proteins enter the nucleus and stimulate the expression of target genes, including OCT4, NANOG and SOX 2 which are transcription factors associated with pluripotency and self-renewal. Activation of Akt also directly phosphorylates OCT4, and as a transcription factor, phosphorylated OCT4 together with phosphorylated SOX2 regulates the transcription of NANOG.

Akt, $\beta$-catenin, inactivated GSK3 $\beta$ (phosphorylated at Ser 9) and total GSK3 $\beta$ was evaluated by western blot analysis.

At $12 \mathrm{~h}$ of treatment, scoparone significantly affected Wnt $/ \beta$-catenin related proteins compared to untreated control cells. In the cells treated with $2.5,5$ and $10 \mu \mathrm{M}$ of the compound, as opposed to controls, phosphorylated Akt was found to increase 1.53- 1.38 - and 1.64-fold $(p<0.05,<0.05$ and $<0.01$ ), respectively. Phosphorylated GSK $3 \beta$ increased by $2.12-, 1.62-$ and 2.14-fold $(p<0.01,0.01$ and $<0.05)$, respectively. In the cells treated with 5 and $10 \mu \mathrm{M}$ of the compound, $\beta$-catenin was significantly increased 1.25 - and 1.45 -fold ( $p<0.001$ and $<0.01$ ), respectively (Figure 4A, C).

In $24 \mathrm{~h}$ of treatment, $10 \mu \mathrm{M}$ of the compound caused induction of phosphorylated Akt 1.72-fold $(p<0.05)$, compared to the control. In the cells treated with 5 and 10 $\mu \mathrm{M}$ of the compound, phosphorylated GSK3 $\beta$ was increased 2.08 - and 1.97 -fold $(p<0.05$ and $<0.05)$, respectively. In the cells treated with 2.5 and $5 \mu \mathrm{M}$ of the compound, $\beta$-catenin was significantly increased by 1.39 - and 1.36 -fold $(p<0.05$ and $<0.05$ ), respectively (Figure $4 \mathrm{~B}, \mathrm{C}$ ). To validate the mechanistic control of PI3K/Akt pathway on $\beta$-catenin and SOX2, as well as test the effect of scoparone on the PI3K/Akt activation, a pharmacological experiment using specific PI3K inhibitors was performed. The cells were treated with scoparone in the presence or absence of specific PI3K inhibitors $50 \mu \mathrm{M}$ LY294002 or $5 \mu \mathrm{M}$ wortmannin and subjected to immunofluorescence analysis for $\beta$-catenin and SOX2 detections. Immunocytochemistry analysis showed that scoparone led to increased $\beta$-catenin and SOX2. Importantly, in the presence of $50 \mu \mathrm{M}$ of LY294002 or $5 \mu \mathrm{M}$ of wortmannin, $\beta$-catenin and SOX2 were found to be reduced (Figure 3A, B). These results indicate that scoparone has positive effects on the stemness of DPCs via the activation of PI3K/Akt-dependent regulation of $\beta$-catenin. 


\section{Discussion}

DPCs play crucial roles in regulating the formation and development of hair follicles; in the mature follicle these cells could form the multipotent stem cell reservoir. The activity and function of DPCs has been demonstrated to be dependent on the stemness of these cells $(4,23,24)$. Wnt/ $\beta$ catenin signaling provides strong support to hair follicle morphogenesis and regeneration (5-7). In addition, Wnt/ $\beta$ catenin is known to be an important coregulator of three master transcription factors (OCT4, NANOG and SOX2) that promote self-renewal of embryonic stem cells (8-10). It has been documented that the hair inducing property of DPCs gradually declines during culture $(25,26)$. The Akt axis has been shown to regulate the survival, growth and inductivity of DPCs (13). In addition, the inhibition of GSK3 $\beta$ using a specific GSK3 $\beta$ inhibitor in DPCs resulted in an activation of Wnt $/ \beta$-catenin pathway and sustained the hair inductive potential (14). Knowing that $\mathrm{Wnt} / \beta$-catenin is important for hair growth and has the ability to promote the three master pluripotency genes, it is likely that it may have a positive role in the stemness of DPCs.

In this study, we show that scoparone was able to preserve DPCs stemness during culture. Treatment of DPCs with scoparone significantly increased the cellular level of pluripotency related genes SOX2 and NANOG, while it had minimal effects on OCT4 (Figure 2B). Wnt/ $\beta$ catenin signalling is important for maintaining stem cell properties $(21,26,27)$. $\beta$-catenin regulates the expression of proteins facilitating stem cell functions by being a coactivator that, combined with T-cell factor/lymphoid enhancing factor (TCF/LEF), results in increased target gene expression (12). The GSK3 $\beta$ functions as $\beta$-catenin's cellular level regulator by phosphorylating $\beta$-catenin, leading to its degradation. Active Akt inhibits GSK3 $\beta$ activity through phosphorylation at serine 9 (12). Subsequently, the activation of Akt results in increased cellular levels of $\beta$-catenin. The up-regulated $\beta$-catenin proteins translocate to the nucleus where they stimulate target genes (Figure 5). In this study, in order to elucidate the mechanism of action of scoparone, we found that scoparone exerted its stemness enhancing activity through the up-regulation of Akt-dependent inhibition of GSK3 $\beta$, as the protein levels of active Akt (phosphorylated Akt) were increased, followed by the induction of inactive GSK3 $\beta$ (Figure 4C). It was shown that GSK3 $\beta$ is responsible for $\beta$-catenin degradation. We further found that the inhibitory effect of scoparone on GSK3 $\beta$ resulted in the increase of cellular levels of $\beta$-catenin, a stem cell controller (Figure 4C). To confirm this mechanism of action of scoparone via the PI3K/Akt pathway, DPCs were pretreated with PI3K inhibitors and the expression of $\beta$ catenin and SOX2 was analyzed by immunocytochemistry.
The results demonstrated that scoparone alone induced the expression of $\beta$-catenin and SOX2, while their expression was found to be reduced in the presence of LY294002 or wortmannin (Figure 3A, B). These results suggest that the stemness sustaining effect of scoparone is due to the activation of the Akt/ $\beta$-catenin pathway. They reveal a novel activity and mechanism of action of scoparone that could facilitate the development of hair enrichment approaches.

\section{Conclusion}

This study provides new information for maintaining the stemness of dermal papilla by scoparone. The effect was mediated through Akt activation. Considering the stemness preserving properties, scoparone appears to be a promising natural agent that warrants further research for potential clinical applications.

\section{Conflicts of Interest}

The Authors declare that there are no conflicts of interest.

\section{Authors' Contributions}

NS, PC and TT performed experiments and drafted the article. NS and TT performed experiments. BS isolated the tested compound. PC designed and supervised the research and wrote the article. PS supervised the research.

\section{Acknowledgements}

This work was supported by the Pan Rajdhevee Group Public Co., Ltd. The authors express their gratitude to the Faculty of Pharmaceutical Sciences, Chulalongkorn University for providing laboratory resources.

\section{References}

1 Madaan A, Verma R, Singh AT and Jaggi M: Review of Hair Follicle Dermal Papilla cells as in vitro screening model for hair growth. Int J Cosmet Sci 40(5): 429-450, 2018. PMID: 30144361. DOI: $10.1111 /$ ics.12489

2 Driskell RR, Clavel C, Rendl M and Watt FM: Hair follicle dermal papilla cells at a glance. J Cell Sci 124(Pt 8): 1179-1182, 2011. PMID: 21444748. DOI: $10.1242 /$ jcs.082446

3 Kiratipaiboon C, Tengamnuay $\mathrm{P}$ and Chanvorachote $\mathrm{P}$ : Ciprofloxacin improves the stemness of human dermal papilla cells. Stem Cells Int 2016: 5831276, 2016. PMID: 26649051. DOI: $10.1155 / 2016 / 5831276$

4 Ziegler AN, Schneider JS, Qin M, Tyler WA, Pintar JE, Fraidenraich D, Wood TL and Levison SW: IGF-II promotes stemness of neural restricted precursors. Stem Cells 30(6): 12651276, 2012. PMID: 22593020. DOI: 10.1002/stem.1095

5 Enshell-Seijffers D, Lindon C, Kashiwagi M and Morgan BA: beta-catenin activity in the dermal papilla regulates morphogenesis and regeneration of hair. Dev Cell 18(4): 633-642, 2010. PMID: 20412777. DOI: 10.1016/j.devcel.2010.01.016 
6 Kishimoto J, Burgeson RE and Morgan BA: Wnt signaling maintains the hair-inducing activity of the dermal papilla. Genes Dev 14(10): 1181-1185, 2000. PMID: 10817753.

7 Shimizu $\mathrm{H}$ and Morgan BA: Wnt signaling through the betacatenin pathway is sufficient to maintain, but not restore, anagen-phase characteristics of dermal papilla cells. J Invest Dermatol 122(2): 239-245, 2004. PMID: 15009701. DOI: 10.1046/j.0022-202X.2004.22224.x

8 Li YQ: Master stem cell transcription factors and signaling regulation. Cell Reprogram 12(1): 3-13, 2010. PMID: 20132009. DOI: $10.1089 /$ cell.2009.0033

9 Sato S, Tomomori-Sato C, Parmely TJ, Florens L, Zybailov B, Swanson SK, Banks CA, Jin J, Cai Y, Washburn MP, Conaway JW and Conaway RC: A set of consensus mammalian mediator subunits identified by multidimensional protein identification technology. Mol Cell 14(5): 685-691, 2004. PMID: 15175163. DOI: 10.1016/j.molcel.2004.05.006

10 Kelly KF, Ng DY, Jayakumaran G, Wood GA, Koide H and Doble BW: $\beta$-catenin enhances Oct-4 activity and reinforces pluripotency through a TCF-independent mechanism. Cell Stem Cell 8(2): 214-227, 2011. PMID: 21295277. DOI: 10.1016/ j.stem.2010.12.010

11 Chen Y, Fan Z, Wang X, Mo M, Zeng SB, Xu RH, Wang X and $\mathrm{Wu} \mathrm{Y}$ : PI3K/Akt signaling pathway is essential for de novo hair follicle regeneration. Stem Cell Res Ther 11(1): 144, 2020. PMID: 32245516. DOI: 10.1186/s13287-020-01650-6

12 Fukumoto S, Hsieh CM, Maemura K, Layne MD, Yet SF, Lee KH, Matsui T, Rosenzweig A, Taylor WG, Rubin JS, Perrella MA and Lee ME: Akt participation in the Wnt signaling pathway through Dishevelled. J Biol Chem 276(20): 17479-17483, 2001. PMID: 11278246. DOI: 10.1074/jbc.C000880200

13 Rastegar H, Ahmadi Ashtiani H, Aghaei M, Ehsani A and Barikbin B: Combination of herbal extracts and platelet-rich plasma induced dermal papilla cell proliferation: involvement of ERK and Akt pathways. J Cosmet Dermatol 12(2): 116-122, 2013. PMID: 23725305. DOI: 10.1111/jocd.12033

14 Soma T, Fujiwara S, Shirakata Y, Hashimoto K and Kishimoto $\mathrm{J}$ : Hair-inducing ability of human dermal papilla cells cultured under Wnt/ $\beta$-catenin signalling activation. Exp Dermatol 21(4): 307-309, 2012. PMID: 22417309. DOI: 10.1111/j.16000625.2012.01458.x

15 Osada A, Iwabuchi T, Kishimoto J, Hamazaki TS and Okochi H: Long-term culture of mouse vibrissal dermal papilla cells and de novo hair follicle induction. Tissue Eng 13(5): 975-982, 2007. PMID: 17341162. DOI: 10.1089/ten.2006.0304

16 Zhang P, Kling RE, Ravuri SK, Kokai LE, Rubin JP, Chai JK and Marra KG: A review of adipocyte lineage cells and dermal papilla cells in hair follicle regeneration. J Tissue Eng 5: 2041731414556850, 2014. PMID: 25383178. DOI: 10.1177/ 2041731414556850

17 Kim JK, Kim JY, Kim HJ, Park KG, Harris RA, Cho WJ, Lee JT and Lee IK: Scoparone exerts anti-tumor activity against DU145 prostate cancer cells via inhibition of STAT3 activity. PLoS One 8(11): e80391, 2013. PMID: 24260381. DOI: 10.1371 /journal.pone. 0080391
18 Choi W, Jang D, Nam S, Park B, Lee $\mathrm{H}$ and Lee S: Antiulcerogenic activity of scoparone on $\mathrm{HCl}$ /ethanol-induced gastritis in rats. Journal of the Korean Society for Applied Biological Chemistry 55(2): 159-163, 2019. DOI: 10.1007/ s13765-012-1023-y

19 Lin Y, Yang Y, Li W, Chen Q, Li J, Pan X, Zhou L, Liu C, Chen C, He J, Cao H, Yao H, Zheng L, Xu X, Xia Z, Ren J, Xiao L, Li L, Shen B, Zhou H and Wang YJ: Reciprocal regulation of Akt and Oct4 promotes the self-renewal and survival of embryonal carcinoma cells. Mol Cell 48(4): 627-640, 2012. PMID: 23041284. DOI: 10.1016/j.molcel.2012.08.030

20 Jafari M, Ghadami E, Dadkhah $\mathrm{T}$ and Akhavan-Niaki $\mathrm{H}$ : PI3k/AKT signaling pathway: Erythropoiesis and beyond. J Cell Physiol 234(3): 2373-2385, 2019. PMID: 30192008. DOI: $10.1002 /$ jcp. 27262

21 Merrill BJ: Wnt pathway regulation of embryonic stem cell selfrenewal. Cold Spring Harb Perspect Biol 4(9): a007971, 2012. PMID: 22952393. DOI: 10.1101/cshperspect.a007971

22 Ito Y, Hamazaki TS, Ohnuma K, Tamaki K, Asashima M and Okochi H: Isolation of murine hair-inducing cells using the cell surface marker prominin-1/CD133. J Invest Dermatol 127(5): 1052-1060, 2007. PMID: 17185982. DOI: 10.1038/sj.jid. 5700665

23 Armstrong L, Hughes O, Yung S, Hyslop L, Stewart R, Wappler I, Peters H, Walter T, Stojkovic P, Evans J, Stojkovic M and Lako M: The role of PI3K/AKT, MAPK/ERK and NFkappabeta signalling in the maintenance of human embryonic stem cell pluripotency and viability highlighted by transcriptional profiling and functional analysis. Hum Mol Genet 15(11): 1894-1913, 2006. PMID: 16644866 . DOI: $10.1093 / \mathrm{hmg} / \mathrm{ddl} 112$

24 Jahoda CA, Horne KA and Oliver RF: Induction of hair growth by implantation of cultured dermal papilla cells. Nature 311(5986): 560-562, 1984. PMID: 6482967. DOI: 10.1038/ $311560 \mathrm{a} 0$

25 Driskell RR, Giangreco A, Jensen KB, Mulder KW and Watt FM: Sox2-positive dermal papilla cells specify hair follicle type in mammalian epidermis. Development 136(16): 2815-2823, 2009. PMID: 19605494 . DOI: $10.1242 /$ dev.038620

$26 \mathrm{Li} \mathrm{J}, \mathrm{Li} \mathrm{J}$ and Chen B: Oct4 was a novel target of Wnt signaling pathway. Mol Cell Biochem 362(1-2): 233-240, 2012. PMID: 22120493. DOI: $10.1007 / \mathrm{s} 11010-011-1148-\mathrm{Z}$

27 Miki T, Yasuda SY and Kahn M: Wnt/ $\beta$-catenin signaling in embryonic stem cell self-renewal and somatic cell reprogramming. Stem Cell Rev Rep 7(4): 836-846, 2011. PMID: 21603945. DOI: $10.1007 / \mathrm{s} 12015-011-9275-1$
Received May 11, 2021

Revised May 30, 2021

Accepted May 31, 2021 